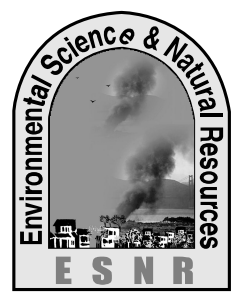

J. Environ. Sci. \& Natural Resources, 5(1): 19 - 28, 2012

ISSN 1999-7361

\title{
Variability and Trend of Seasonal Climatic Variables in Dinajpur District
}

\author{
J. A. Syeda \\ Department of Statistics \\ Hajee Mohammad Danesh Science and Technology University, Dinajpur
}

\begin{abstract}
An attempt was made to investigate the seasonal (three crop seasons) trend and variability of 20 climatic variables of Dinajpur district for 1948-2004. The variety of Exploratory Data Analyses (EDA) tools and different robust and nonrobust measures are used for the analyses. The rates of total rainfall are observed positive for all the three seasons but the residuals are nonormal and/or nonstationary. The rates were found significant positive for average dry bulb temperature $\left(+0.00655^{0} \mathrm{Cyr}^{-1}\right)$ but negative for total frequency of zero rainfall (-0.0846daysyr $\left.{ }^{-1}\right)$ during Kharif season and significant positive for average minimum temperature $\left(+0.0175^{0} \mathrm{Cyr}^{-1}\right)$ but negative for range temperature $\left(-0.0456^{0} \mathrm{Cyr}^{-1}\right)$ and maximum temperature $\left(-0.0281^{0} \mathrm{Cyr}^{-1}\right) \mathrm{during}^{\mathrm{Rabi}}$ season. Historical climatic data needs exploratory analysis and warrants tougher justification in classical analyses for outlier and residual's nonnormality and nonstationarity.
\end{abstract}

Key words: Climate, Temperature, Variability

\section{Introduction}

Climate indicates the long term average weather conditions of a specific area of the earth while weather is the state of the atmosphere at a specific time. Climatic parameters may vary with space and time. Climate change means change of frequency and intensity pattern among the climatic factors such as precipitation, temperature, sunlight, wind etc. In a particular place, climatic variables may vary for both the within and between years. Agriculture, irrigated or rainfed, is inherently vulnerable to climatic hazards (Lenka, 1998). Food shortage can occur due to a sharp decline in production resulting from adverse climatic factors such as extended drought, floods and/or cyclones. Talukder et al. (1988), Ahmed and Karmakar (1993), Ali et al. (1994) tried to detect and measure rainfall variability within years but overlooked the possibility of the between-years variability. Rahman and Alam (1996) and Karmakar (2001) made some efforts in this area, but their studies lack modern statistical techniques. There is a scope to examine whether the trends under study are deterministic or stochastic by checking in the model adequacy. Rahman and Alam (1996) examined the trend pattern of annual and seasonal rainfall over the last 16 years of all of the high Barind districts in Bangladesh by using simple regression techniques. Not even the normality and stationarity of residuals were checked in their studies. Dinajpur is the highest wheat producing area of Bangladesh. So, a clear understanding of climate of Dinajpur is necessary for their production. In this paper, an attempt was taken to study the trend and variability of seasonal climatic variables in Dinajpur district mainly by using the exploratory data analytic tools.

\section{Data and Methodology}

\section{Sources of data}

The daily and monthly data for 1948-1972 and 19812004 on climatic factors of Dinajpur district were collected from the Bangladesh Meteorological Department, Agargaon, Dhaka, Bangladesh. The collected data were the total rainfall in mm (TR) and maximum rainfall (MXR) in $\mathrm{mm}$, total frequency of insignificant rainfall in days (TFIR), total frequency of zero rainfall (TFZR), average dry bulb temperature in ${ }^{0} \mathrm{C}$ (ADBT), average maximum temperature in ${ }^{0} \mathrm{C}$ (AMXT), average minimum temperature in ${ }^{0} \mathrm{C}$ (AMNT), average range temperature in ${ }^{0} \mathrm{C}$ (ARNT), average wet bulb temperature in ${ }^{0} \mathrm{C}$ (AWBT), average difference of dry bulb and wet bulb temperature in ${ }^{\circ} \mathrm{C}$ $\{\mathrm{AT}(\mathrm{D}-\mathrm{W})\}$, average relative humidity in percentage $(\mathrm{ARH})$, average difference of relative humidity between morning and evening in percentage $(\mathrm{ARH}(0-$ 12)), average wind speed in knots (AWS), average maximum wind speed in knots (AMWS), average sea level pressure in mb (ASLP), average cloud in octas (AC). Besides, the data of daily and monthly evaporation in percentage (AE) during 1987-2000, average soil temperature (AST) in ${ }^{0} \mathrm{C}$ at the depths of $5,10,20,50 \mathrm{~cm}$, respectively during 1987-2000 and the average sunshine-hour (ASH) during 1989-2004 were collected. In this study, the daily and the monthly missing data for 1973-1976 were filled in by the medians of the observed data for 1948-1972 and the missing data for 1977-1980 were filled in by the medians of the observed data for 1981-2004. Daily missing values were placed by the median of the corresponding daily data of the months/years. Seasonal data were produced in accordance with the agricultural season in Bangladesh such as (1) Rabi = 
November-February, (2) Pre-kharif = March-May and (3) Kharif = June-October.

\section{Methodology}

The within-year and between-year seasonal and monthly patterns were investigated for the data for 1948-2004 with the exploratory data analyses techniques like boxplot, stem-and-leaf plot, and median polish table. The statistical package Minitab 11.12 was used for the analysis. The nonrobust measures like mean, coefficient of variation and robust measures like median, 5\% trimmed mean and the percentage ratio of quartile deviation to median were used to investigate the withinyear variability pattern of data. Boxplots were considered primarily and to determine between-year seasonal and monthly variation and effects of climatic variables, year-season and year month two-way classification table were constructed and median polish are employed on it. The trend of the number of weeks containing $0-5$ millimeter $(\mathrm{ml})$ rainfall were investigated as it is considered insignificant from agricultural view and this analysis can focus about the drought. To test whether the trend is deterministic or stochastic, the stationarity of residuals were checked after trend fitting using the sample autocorrelation function (ACF) and from the partial autocorrelation function (PACF) and Box-Peirce test statistic. The normality of the residuals were examined from these fits by normal probability plot and the rescaled moments (RM) test for normality (Imon, 2003).

\section{Exploratory Data Analysis (EDA) and Robust Techniques}

Exploratory data analysis methods were used primarily to explore data before using more traditional methods, or to examine residuals from a model. These methods are particularly useful for identifying extraordinary observations and noting violations of traditional assumptions, such as nonlinearity or nonconstant variance. Tukey (1977) demonstrated ample weakness of classical parametric statistics to handle real world data due to its strong dependence on extraneous assumptions and advocated using the EDA methods. EDA is a set of techniques which are primarily used to explore data before using more traditional methods, or to examine residuals from a model. It employs a variety of techniques to maximize insight into a data set, uncovers underlying structure, extracts important variables, detects outliers and anomalies, tests underlying assumptions, develops parsimonious models and determines optimal factor setting. Most EDA techniques are graphical with a few quantitative techniques. The reason for the heavy reliance on graphics is that graphics is the best means through

which data can speak itself without assumptions, models, hypotheses and even concept of probability. Boxplots are used to assess and compare sample distributions. This plot consists of the so called five number summary (median, first and third quartiles, and upper and lower inter-quartile ranges). Here it is tried to plot the data in a box whose midpoint is the sample median, the top of the box is the third quartile (Q3) and the bottom of the box is the first quartile (Q1). The upper whisker extends to this adjacent value- the highest data value within the upper limit $=$ Q3 + 1.5 (Q3 - Q1). Similarly the lower whisker extends to this adjacent value- the lowest value within the lower limit = Q1- 1.5 (Q3 - Q1). An observation is considered to be unusually large or small when it is plotted beyond the whiskers and those are treated as outliers. The stem-and-leaf plot is used to examine the shape and spread of the sample data. The plot is similar to a histogram on its side, nonetheless, instead of bars, digits from the actual data values indicate the frequency of each bin (row) and thus it becomes more informative than the histogram. Median Polish fits an additive model to a two-way design and identifies data patterns not explained by row and column effects. This procedure is similar to analysis of variance except medians are used instead of means, thus adding robustness against the effect of outliers. The term robustness signifies insensitivity to small deviations from the assumption. That means a robust procedure is nearly as efficient as the classical procedure when classical assumptions hold strictly but is considerably more efficient over all when there is a small departure from those. The main application of robust techniques is to try to devise estimators, which are not strongly affected by outliers in a sense that the robust techniques can cope with outliers by keeping small the effects of their presence. The EDA techniques considered in this paper are very robust, but are mainly designed for graphical display. In a quantitative analysis, robust estimates of location and dispersion are often required. As an estimator of location parameter, median are used instead of mean. But it is now evident (Alam et al., 2003) that when contamination is not high, trimmed mean (TRM) performs better than the median. As an estimator of scale parameter, the median absolute deviation (MAD) is used instead of the standard deviation. The robust version of the relative measure of dispersion like the coefficient of variation $(\mathrm{CV})$ is found where mean and standard deviations are replaced by median (or trimmed mean). Again the percentage ratio of quartile deviation (QD) to median is used instead of MAD. 


\section{Results}

The seasonal climatic data of Dinajpur are analyzed over the years. The boxplots for the data of some variables are shown in Fig.1 (1- Rabi season, 2-
Prekharif season and 3- Kharif season). The boxplot of TR in Fig.1 shows that both the median and variations of TR are highest in Kharif season by a large extent while the lowest variation in Rabi season.
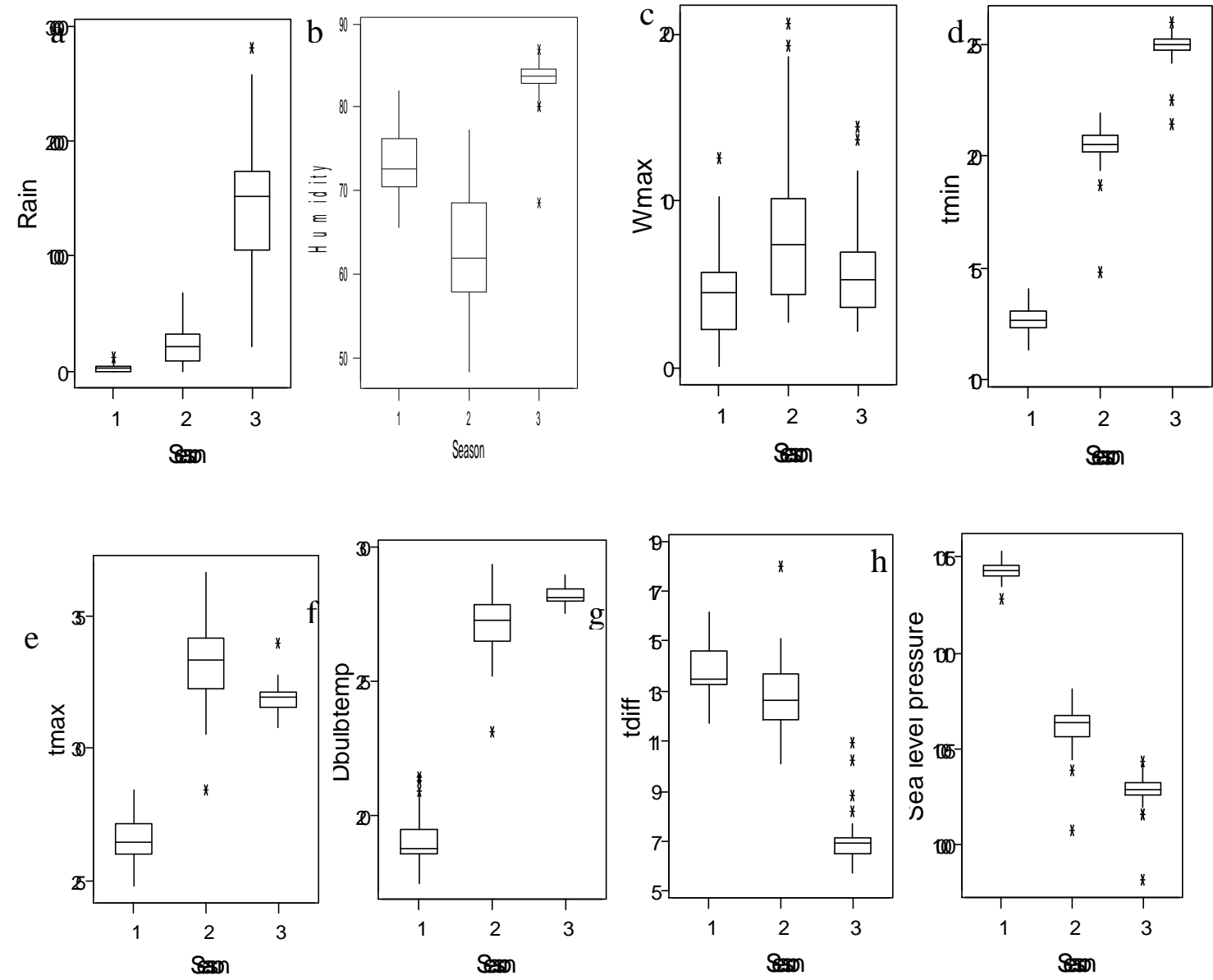

Fig. 1. Boxplot of seasonal (a) TR (b) ARH (c) AMWS (d) AMNT(e) AMXT(f) ADBT (g) ARNT (h) ASLP 


\section{J. Environ. Sci. \& Natural Resources, 5(1): 19-28, 2012}

Table 1 presents the lower outliers (LO) and the higher (HI) outliers for seasonal climatic variables obtained from stem-and-leaf displays and the occurrences years for extreme outliers. The higher outlier of TR was observed $123 \mathrm{~mm}$ in 1981 for Rabi season and the higher outlier was 2800 in 1987 for kharif season.

Table 1. Detected outliers and the occurrences years for extreme outliers of seasonal variables

\begin{tabular}{|c|c|c|c|}
\hline Issues & Rabi & Prekharif & Kharif \\
\hline TR & $\begin{array}{l}\text { (HI: 123) Leaf Unit }=1.0 \\
\text { HI: } 123-1981\end{array}$ & - & $\begin{array}{l}\text { (HI: 28) Leaf Unit }=100 \\
\text { HI: } 28-1987\end{array}$ \\
\hline AWS & $\begin{array}{l}\text { (HI: 308) Leaf Unit }=0.010 \\
\text { HI: } 308-1981\end{array}$ & $\begin{array}{l}\text { (HI: 59) Leaf Unit }=0.10 \\
\text { HI: 59-1981 }\end{array}$ & $\begin{array}{l}\text { (HI: 31) Leaf Unit }=0.10 \\
\text { HI: } 31-1981\end{array}$ \\
\hline AMWS & $\begin{array}{l}\text { (HI: 125) Leaf Unit }=0.10 \\
\text { HI: } 125-1981\end{array}$ & $\begin{array}{l}\text { (HI: } 186,193,206) \\
\text { Leaf Unit }=0.10 \\
\text { HI: } 206-1992\end{array}$ & $\begin{array}{l}\text { (HI: } 118,136,144) \text { Leaf Unit }=0.10 \\
\text { HI: } 144-1971\end{array}$ \\
\hline ASLP & $\begin{array}{l}\text { (LO: 10128)Leaf Unit }=0.10 \\
\text { LO: } 10128-1985\end{array}$ & $\begin{array}{l}(\text { LO: } 10007,10039) \\
\text { Leaf Unit }=0.10 \\
\text { LO: } 10007-1948\end{array}$ & $\begin{array}{l}\text { (LO: } 9981,10015,10016 \text { and } \\
\text { HI: } 10041,10042,10043) \text { Leaf Unit }=0.10 \\
\text { LO: } 9981-1959 \text { and } \\
\text { HI: } 10043-1997\end{array}$ \\
\hline ARH & - & - & $\begin{array}{l}\text { (LO: } 684,800,801,808,809,810,812, \\
812 \text { and HI: } 866,869) \text { Leaf Unit }=0.10 \\
\text { LO: } 684-1981 \text { and HI: } 869-1999\end{array}$ \\
\hline AWBT & - & $\begin{array}{l}\text { (LO: 183) Leaf Unit }=0.10 \\
\text { LO: } 183-1981\end{array}$ & $\begin{array}{l}\text { (LO: } 2350 \text { and HI: 2690, 2694) } \\
\text { Leaf Unit }=0.010 \\
\text { LO: } 2350-1981 \text { and } \\
\text { HI: } 2694-1998\end{array}$ \\
\hline ADBT & $\begin{array}{l}\text { (HI: 208, 209, 213, 214) } \\
\text { Leaf Unit }=0.10\end{array}$ & (LO: 231) Leaf Unit $=0.10$ & - \\
\hline ARNT & - & (HI: 180) Leaf Unit $=0.10$ HI: $180-1957$ & (HI: $82,88,102,109)$ Leaf Unit $=0.10$ HI: $109-1981$ \\
\hline AMNT & $\begin{array}{l}\text { (LO: } 113,113,114 \text { and } \\
\text { HI: } 140,140) \text { Leaf Unit }= \\
0.10 \\
\text { LO: } 113(2)-1949,1950 \text { and } \\
\text { HI: } 140(2)-1999\end{array}$ & $\begin{array}{l}\text { (LO: } 148,186 \text { and HI: } 218) \\
\text { Leaf Unit }=0.10 \\
\text { LO: } 148-1981 \text { and } \\
\text { HI: } 218-1970\end{array}$ & $\begin{array}{l}\text { (LO: } 2138,2252,2413 \text { and HI: 2594) } \\
\text { Leaf Unit }=0.010 \\
\text { LO: } 2138-1981 \text { and HI: 2594- } 1998\end{array}$ \\
\hline AMXT & - & (LO: 284) Leaf Unit $=0.10$ LO: $284-1981$ & (HI: 339) Leaf Unit $=0.10$ HI: 339- 1972 \\
\hline
\end{tabular}

Table 2 presents the numerical values of the variability of seasonal data in respect of nonrobust means and CVs. The TR shows the highest mean in Kharif

The variables of AC, AMNT, ADBT, AWBT and AST(5) also show largest mean in Kharif season and smallest in Rabi season while the highest variation in Rabi season and lowest in Kharif season. The variables AMWS, AWS and ASLP show the highest mean in Prekharif season and lowest in Rabi season while the utmost variation in Rabi season and the lowest in Kharif season.

The AMXT shows the uppermost mean in Prekharif season and lowest in Rabi season while the highest variation in Prekharif season and the lowest in Kharif season. The ARNT shows the top mean in Rabi season and lowest in Kharif season whereas the maximum variation in Kharif season and the least in season and lowest mean in Rabi season while the highest variation in Rabi season and the lowest variation in Kharif season.

Rabi season. The AT(D-W) shows the largest mean in Prekharif season and the smallest in Kharif season but the peak variation in Prekharif season and the least in Kharif season.

The variables ARH, ARH (12) and ARH (0) show the utmost mean in Kharif season and the lowest in Prekharif season while the utmost variation is observed in Prekharif season and the smallest is found in Kharif season. The variables ARH (0-12) and ASH show the uppermost mean in Prekharif season and the buck in Kharif season whereas the maximum variation in Kharif season and the slightest in Rabi season are noted. 
The variable ASLP shows the largest mean in Rabi season and the smallest in Kharif season on the other hand, major variation in Prekharif season and the lowly in Rabi season. The variable AE shows the topmost mean in Prekharif season and the least in
Rabi season yet the highest variation in Prekharif season and the lowest in Rabi season.

The boxplots of ARH, AMWS, AMNT, AMXT, ADBT, ARNT and ASLP in Fig. 1 show the similar pattern with the numerical indices.

Table 2. Variability for seasonal data

\begin{tabular}{|c|c|c|c|c|c|c|c|c|c|c|c|c|c|c|}
\hline Variable & Season & Rabi & Prekharif & Kharif & Variable & Season & Rabi & Prekharif & Kharif & Variable & Season & \begin{tabular}{|l|} 
Rabi \\
\end{tabular} & \begin{tabular}{|l} 
Prekharif \\
\end{tabular} & Kharif \\
\hline \multirow{2}{*}{ TR } & Mean & 27.82 & 214.30 & 1395 & \multirow{2}{*}{ AT (D-W) } & Mean & 3.00 & 5.37 & 2.14 & \multirow{2}{*}{ AMWS } & Mean & 4.27 & 7.91 & 5.80 \\
\hline & $\mathrm{CV}$ & 109.78 & 77.65 & 43.35 & & $\mathrm{CV}(\%)$ & 17.84 & 24.77 & 17.50 & & $\mathrm{CV}(\%)$ & 60.15 & 52.81 & 47.91 \\
\hline \multirow{2}{*}{ AC } & Mean & 0.86 & 2.33 & 4.80 & \multirow{2}{*}{ ASH } & Mean & 7.09 & 7.51 & 14.53 & \multirow{2}{*}{ AWS } & Mean & 0.71 & 1.71 & 1.24 \\
\hline & $\mathrm{CV}$ & 45.09 & 26.57 & 8.29 & & $\mathrm{CV}(\%)$ & 7.21 & 7.33 & 12.34 & & $\mathrm{CV}(\%)$ & 87.01 & 50.32 & 47.67 \\
\hline \multirow{2}{*}{ AMNT } & Mean & 12.71 & 20.43 & 24.89 & \multirow{2}{*}{ ARH } & Mean & 3.00 & 5.37 & 5.35 & \multirow{2}{*}{ AMXT } & Mean & 26.52 & 33.13 & 31.87 \\
\hline & $\mathrm{CV}$ & 5.13 & 4.81 & 2.72 & & $\mathrm{CV}(\%)$ & 17.84 & 24.77 & 9.54 & & $\mathrm{CV}(\%)$ & 2.85 & 4.56 & 1.57 \\
\hline \multirow{2}{*}{ ADBT } & Mean & 19.04 & 27.12 & 28.20 & \multirow{2}{*}{ ARH(12) } & Mean & 26.91 & 32.05 & 2.14 & & Mean & 22.61 & 50.33 & 35.69 \\
\hline & $\mathrm{CV}$ & 4.41 & 4.16 & 1.16 & & $\mathrm{CV}(\%)$ & 11.30 & 12.04 & 17.50 & & $\begin{array}{ll}\mathrm{CV}(\%) \\
\end{array}$ & 7.83 & 14.33 & 13.11 \\
\hline \multirow{2}{*}{ AWBT } & Mean & 16.04 & 21.75 & 26.06 & \multirow{2}{*}{$\mathrm{ARH}(0)$} & Mean & 7.09 & 7.51 & 14.53 & \multirow{2}{*}{ ARNT } & Mean & 13.81 & 12.70 & 6.98 \\
\hline & $\mathrm{CV}$ & 4.05 & 3.82 & 1.73 & & $\mathrm{CV}(\%)$ & 7.21 & 7.33 & 12.34 & & $\mathrm{CV}$ & 6.94 & 11.49 & 12.60 \\
\hline \multirow{2}{*}{ AST(5) } & Mean & 19.47 & 27.73 & 29.95 & \multirow{2}{*}{$\operatorname{ARH}(0-12)$} & Mean & 26.91 & 32.05 & 5.35 & \multirow{2}{*}{ ASLP } & Mean & 1014.3 & 1006.2 & 1002.9 \\
\hline & $\mathrm{CV}$ & 3.52 & 3.33 & 1.21 & & $\mathrm{CV}(\%)$ & 11.30 & 12.04 & 9.54 & & $\mathrm{CV}$ & 0.05 & 0.12 & 0.09 \\
\hline
\end{tabular}

The variability of the maximum values of seasonal variables is presented in Table 3 . The peak TR in Kharif season is observed as $2819 \mathrm{~mm}$ while it is 673 $\mathrm{mm}$ in Prekharif season and $123 \mathrm{~mm}$ in Rabi season. The highest AC in Kharif season is 5.62 while it is 3.67 in Prekharif season and 1.98 octas in Rabi season. The largest AWS and AMWS are found 5.93 and 20.67knots in Prekharif season while these are 3.10 and 14.40 knots in Kharif season and 3.08 and 12.5 knots in Rabi season. The uppermost ASLP in Rabi season is 1015.40 while it is 1008.20 in Prekharif season and $1004.30 \mathrm{mb}$ in Kharif season. The highest AE in Prekharif season is 63.67 percent while it is 40.8 percent in Kharif season and 25.5 percent in Rabi season. The largest ASH in Prekharif season is 8.532 while it is 8 in Kharif season and 6.194 in Kharif season.

The maximum ARH and ARH (12) are found 86.97 and 82.54 percent in Kharif season while these are 82.02 and 75.5 percent in Rabi season and 77.02 and 69.33 percent in Prekharif season. The highest ARH (0) is 97.28 in Rabi season while it is 95.69 in Kharif season and is 92.81 percent in Prekharif season. The largest $\mathrm{ARH}(0-12)$ is 42.41 in Prekharif season while it is 32.61 in Rabi season and 21.07 percent in Kharif season.

The uppermost ADBT, AMXT and AT (D-W) are obtained 29.36, 36.67 and $8.44^{\circ} \mathrm{C}$ in Prekharif season while these are $28.97,33.94$ and $4.31^{\circ} \mathrm{C}$ in Kharif season and 21.44, 28.4 and $4.2^{\circ} \mathrm{C}$ in Rabi season. The highest AMNT is observed 25.94 in Kharif season while it is 21.88 in Prekharif season and $14.08^{\circ} \mathrm{C}$ in Rabi season. The largest ARNT is experienced 18.00 in Prekharif season while it is 16.14 in Rabi season and $10.91^{\circ} \mathrm{C}$ in Kharif season.

The topmost values of AST $(5 \mathrm{~cm})$, AST $(20 \mathrm{~cm})$, AST $(30 \mathrm{~cm})$ and AST $(50 \mathrm{~cm})$ are originated as 30.92 , $31.12,30.74$ and $30.39^{\circ} \mathrm{C}$ in Kharif season while these are 28.93, 28.87, 28.33 and $27.57^{\circ} \mathrm{C}$ in Prekharif season and 20.96, 21.71, 22.02 and $22.47^{\circ} \mathrm{C}$ in Rabi season. 


\section{J. Environ. Sci. \& Natural Resources, 5(1): 19-28, 2012}

Table 3. Variability of maximum values for seasonal data

\begin{tabular}{|l|l|l|l|l|l|l|l|l|l|l|l|}
\hline Issues & $\mathbf{R}$ & $\mathbf{P k}$ & $\mathbf{K}$ & Issues & $\mathbf{R}$ & $\mathbf{P k}$ & $\mathbf{K}$ & Issues & $\mathbf{R}$ & Pk & K \\
\hline TR & 123 & 673 & 2819 & AMWS & 12.5 & 20.67 & 14.4 & ADBT & 21.44 & 29.36 & 28.97 \\
\hline TFIR & 121 & 92 & 121 & ASLP & 1015.4 & 1008.2 & 1004.3 & AMNT & 14.08 & 21.88 & 25.94 \\
\hline TFZR & 121 & 92 & 103 & ARH & 82.02 & 77.27 & 86.97 & AMXT & 28.40 & 36.67 & 33.94 \\
\hline MXR & 92 & 186 & 858 & ARH(0) & 97.28 & 92.81 & 95.69 & ARNT & 16.14 & 18.00 & 10.91 \\
\hline AC & 1.98 & 3.67 & 5.62 & ARH(12) & 75.5 & 69.33 & 82.54 & AWBT & 17.52 & 23.43 & 26.94 \\
\hline AWS & 3.08 & 5.93 & 3.10 & ARH(0-12) & 32.61 & 42.41 & 21.07 & AT(D-W) & 4.20 & 8.44 & 4.31 \\
\hline
\end{tabular}

$\mathbf{R}=$ Rabi, $\mathbf{P k}=$ Prekharif, $\mathbf{K}=$ Kharif

The variabilities of minimum values of seasonal variables are presented in Table 4. The lowest amount of TR is $0 \mathrm{~mm}$ in both the Rabi and Prekharif seasons and $211 \mathrm{~mm}$ in Kharif season. The least AC in Rabi season is 0.200 while it is 1.00 in Prekharif season and 3.8 octas in Kharif season. The lowest AWS and AMWS in Rabi season is found to be 0.00 knots while these are 0.32 and 2.20 knots in Kharif season and 0.43 and 2.67 knots in Prekharif season. The lowly ASLP in Kharif season is 998.10 while it is 1000.7 in Prekharif season and $1012.9 \mathrm{mb}$ in Rabi season. The least amount of AE in Rabi season is $19.25 \%$ while it is $35.33 \%$ in Parkharif season and $25 \%$ in Kharif season. The least ASH in Kharif season is 4.456 while it is 6.341 in Parkharif season and 6.365 in Kharif season.

The slightest ARH, ARH (0) and ARH (12) are 48.22, 71.34 and $33.27 \%$ in Prekharif season while these are 65.42, 85.14 and 56.35 in Rabi season and $68.43,87.98$ and 66.9 percent is in Kharif season. The lowest ARH (0-12) is 10.33 in Kharif season while it is 18.22 in Rabi season and 22.22 percent in Prekharif season.

The minimum ADBT, AMNT, AMXT and AWBT are observed $17.49,11.34,24.75$ and $14.8^{\circ} \mathrm{C}$ in Rabi season while $23.11,14.81,28.43$ and $18.33^{\circ} \mathrm{C}$ in Prekharif season and $27.52,21.38,30.75$ and $23.5^{\circ} \mathrm{C}$ in Kharif season. The lowest ARNT is 5.73 in Kharif season while it is 10.07 in Parkharif season and $11.75^{\circ} \mathrm{C}$ in Rabi season. The least AT (D-W) is found as 1.65 in Kharif season while it is 1.88 in Rabi season and $2.72^{\circ} \mathrm{C}$ in Prekharif season.

The smallest values of AST $(5 \mathrm{~cm})$, AST $(20 \mathrm{~cm})$, AST $(30 \mathrm{~cm})$ and AST $(50 \mathrm{~cm})$ are experienced 18.41, 19.7920 .05 and $20.16^{\circ} \mathrm{C}$ in Rabi season, 25.86, 26.16, 25.71 and $25.45^{\circ} \mathrm{C}$ in Prekharif season and $29.4,29.72,29.1$ and $29.23^{\circ} \mathrm{C}$ in Kharif season, respectively.

Table 4. Variability of minimum values for seasonal data

\begin{tabular}{|c|c|c|c|c|c|c|c|c|c|c|c|}
\hline Issues & $\mathbf{R}$ & $\mathbf{P k}$ & $\mathbf{K}$ & Issues & $\mathbf{R}$ & $\mathbf{P k}$ & $\mathbf{K}$ & Issues & $\mathbf{R}$ & $\mathbf{P k}$ & $\mathbf{K}$ \\
\hline TR & 0 & 0 & 211 & ARH & 65.4 & 48.2 & 68.4 & ADBT & 17.4 & 23.1 & 27.5 \\
\hline MXR & 0 & 0 & 37 & $\operatorname{ARH}(12)$ & 56.35 & 33.27 & 66.9 & AMNT & 11.3 & 14.8 & 21.3 \\
\hline TFIR & 113 & 70 & 83 & $\operatorname{ARH}(\mathbf{0})$ & 85.1 & 71.3 & 87.9 & AMXT & 24.7 & 28.4 & 30.7 \\
\hline TFZR & 110 & 63 & 55 & $\operatorname{ARH}(0-12)$ & 18.2 & 22.2 & 10.3 & ARNT & 11.75 & 10.07 & 5.73 \\
\hline AC & 0.2 & 1 & 3.8 & ASLP & 1012.9 & 1000.7 & 998.2 & AWBT & 14.8 & 18.3 & 23.5 \\
\hline AWS & 0 & 0.4 & 0.3 & ADBT & 17.4 & 23.1 & 27.5 & $\operatorname{AT}(D-W)$ & 1.8 & 2.7 & 1.6 \\
\hline AMWS & 0 & 2.6 & 2.2 & AMNT & 11.3 & 14.8 & 21.3 & - & - & - & - \\
\hline
\end{tabular}

R = Rabi, Pk = Prekharif, $\mathrm{K}=$ Kharif

Table 5 presents the seasonal effect obtained from the median polish table. The positive seasonal effect is experienced in Kharif season while negative in Rabi season for the variables TR, AMNT, ADBT, AWBT and AC. The variables of ARNT and ASLP show the 


\section{J. Environ. Sci. \& Natural Resources, 5(1): 19-28, 2012}

positive seasonal effect in Rabi season but negative in Kharif season.

The variables of AMXT, AMWS and AWS show the negative seasonal effect in Rabi season and positive seasonal effect in Prekharif season. The negative seasonal effect in Prekharif season and positive seasonal effect in Kharif season are determined in ARH.

Table 5. Seasonal effect obtained from median polish table for seasonal data

\begin{tabular}{|c|c|c|c|c|c|c|c|c|c|c|c|}
\hline Season & TR & AMNT & ADBT & AWBT & AC & ARNT & ASLP & AMXT & AMWS & AWS & ARH \\
\hline Rabi & -153 & -7.71 & -8.14 & -5.78 & -1.4 & 1.23 & 7.98 & -5.08 & -0.92 & -0.48 & 0 \\
\hline Prekharif & 0 & 0 & 0 & 0 & 0 & 0 & 0 & 1.26 & 1.4 & 0.41 & -9.42 \\
\hline Kharif & 1226 & 4.44 & 0.93 & 4.293 & 2.5 & -5.53 & -3.33 & 0 & 0 & 0 & 11.08 \\
\hline
\end{tabular}

Table 6 presents the rates of LT for Rabi climatic variables with the residual's stationarity and normality, and the respective $t$ values. During Rabi season, the significant positive rates are documented for AWBT $\left(+0.0237^{*}\right)$, AC $\left(+0.0136^{*}\right)$ and AMNT $\left(+0.0175^{*}\right)$ but significant negative for ARNT ($\left.0.0456^{*}\right)$, AMXT $\left(-0.0281^{*}\right)$ and TFZR $\left(-0.0180^{*}\right)$ and approximately negative for $\mathrm{AE}(\underline{-0.196})$ and
ASLP (-0.0068). The fairly high positive rates for ARH(12) (+0.282), ARH(0) (+0.160), AMWS (+ $0.0856) \mathrm{ARH}(+0.126), \mathrm{MXR}(+0.414), \mathrm{TR}(+0.547)$, AST(5) (+0.0760) and ADBT (+0.0108) but negative for $\operatorname{ARH}(0-12)(-0.122), \operatorname{AT}(\mathrm{D}-\mathrm{W})(-0.0129)$ and TFIR (-0.0310) and less negative for ASSH (-0.0125) with nonnormal and/or nonstationary residual, respectively.

Table 6. Rates of LT for the data of rabi season and the residual's stationarity and normality

\begin{tabular}{|c|c|c|c|}
\hline Variable & Rabi & Variable & Rabi \\
\hline AWBT & $+0.0237 *(\mathrm{t}=5.64$, Ap. $\mathrm{N}, \mathrm{S})$ & ADBT & $+0.0108(\mathrm{t}=1.62$, Ap. $\mathrm{N}, \mathrm{NS})$ \\
\hline AC & $+0.0136^{*}(\mathrm{t}=5.30$, Ap.N, S $)$ & ARNT & $-0.0456^{*}(\mathrm{t}=-9.54$, Ap. $\mathrm{N}, \mathrm{S})$ \\
\hline AMNT & $+0.0175^{*}(\mathrm{t}=3.68, \mathrm{~N}, \mathrm{~S})$ & AMXT & $-0.0281 *(t=-5.82, \mathrm{~N}, \mathrm{~S})$ \\
\hline $\operatorname{ARH}(12)$ & $+0.282(\mathrm{t}=11.31$, Ap. $\mathrm{N}, \mathrm{NS})$ & TFZR & $-0.0180 *(\mathrm{t}=3.57, \mathrm{~N}, \mathrm{~S})$ \\
\hline $\operatorname{ARH}(0)$ & $+0.160(\mathrm{t}=10.54, \mathrm{NN}, \mathrm{NS})$ & $\mathbf{A E}$ & $\underline{-0.196}(\mathrm{t}=-1.81, \mathrm{~N}, \mathrm{~S})$ \\
\hline AMWS & $+0.0856(\mathrm{t}=4.92, \mathrm{NN}, \mathrm{NS})$ & ASLP & $-\underline{0.0068}(\mathrm{t}=-1.78, \mathrm{~N}, \mathrm{Ap} . \mathrm{S})$ \\
\hline ARH & $+0.126(\mathrm{t}=4.41$, Ap. $\mathrm{N}, \mathrm{NS})$ & $\operatorname{ARH}(0-12)$ & $-0.122(\mathrm{t}=-6.59$, Ap. N, NS) \\
\hline MXR & $+0.414(\mathrm{t}=2.54, \mathrm{NN}, \mathrm{S})$ & $\mathbf{A T}(\mathbf{D}-\mathbf{W})$ & $-0.0129(\mathrm{t}=-3.23$, Ap.N, NS $)$ \\
\hline TR & $+0.547(\mathrm{t}=2.31, \mathrm{NN}, \mathrm{S})$ & TFIR & $-0.0310(\mathrm{t}=-2.10, \mathrm{NN}, \mathrm{S})$ \\
\hline $\operatorname{AST}(5 \mathrm{~cm})$ & $+0.0760(\mathrm{t}=1.81, \mathrm{NN}, \mathrm{S})$ & ASSH & $-0.0125(\mathrm{t}=-0.44, \mathrm{~N}, \mathrm{NS})$ \\
\hline
\end{tabular}

* Significant at 5\% level of significance, The underlineed values are approximately significant N- normal S-Stationary NN-nonnormal NS-Nonstationary Ap. N- Approximately normal

Table 7 presents the rates of LT for Prekharif climatic variables and the Residual's Stationarity and Normality. During Prekharif season, the significant positive growth rates are allowed for $\mathrm{ARH}(0)$ $\left(+0.219^{*}\right), \mathrm{ARH}\left(+0.252^{*}\right)$ and ARH $(12)\left(+0.271^{*}\right)$ but negative for ARNT $\left(-0.0538^{*}\right)$, AT (D-W) $\left.0.0476^{*}\right)$, AMXT $\left(-0.0475^{*}\right)$, ADBT $\left(-0.0270^{*}\right)$ and TFIR (-0.113*); approximately significant positive for AST (5) (+0.0880) but negative for ARH (0-12)
(-0.0521); fairly high positive rates for $\mathrm{AC}$ (+ 0.0234), AMWS (+ 0.116), AWBT (+0.0207) and TR $(+2.39)$ but negative for TFZR (-0.639) and AE (0.777 ) with nonnormal and/nonstationary residual; less positive for MXR (+0.424) and AMNT $(+0.00625)$ but negative for ASLP (-0.00041) with nonnormal and/nonstationary residual. The negative growth rates are permitted for ASSH (-0.030) with normal and stationary residual. 


\section{J. Environ. Sci. \& Natural Resources, 5(1): 19-28, 2012}

Table 7. Rates of LT for the data of prekharif season and the residual's stationarity and normality

\begin{tabular}{|c|c|c|c|}
\hline Variable & Prekharif & Variable & Prekharif \\
\hline $\mathbf{A R H}(\mathbf{0})$ & $+0.219 *(\mathrm{t}=6.86$, Ap N, S $)$ & ARNT & $-0.053 *(t=-5.73$, Ap. $N, S)$ \\
\hline ARH & $+0.252 *(\mathrm{t}=5.39$, Ap.N, Ap.S $)$ & AT(D-W) & $-0.047 *(\mathrm{t}=-5.49$, Ap. $\mathrm{N}, \mathrm{S})$ \\
\hline $\operatorname{ARH}(12)$ & $+0.271 *(\mathrm{t}=5.09, \mathrm{~N}, \mathrm{~S})$ & AMXT & $-0.047 *(\mathrm{t}=-4.55$, Ap. $\mathrm{N}, \mathrm{S})$ \\
\hline $\operatorname{AST}(5 \mathrm{~cm})$ & $+\underline{0.088}(\mathrm{t}=1.51, \mathrm{~N}, \mathrm{~S})$ & ADBT & $-0.027 *(\mathrm{t}=-3.21$, Ap. $\mathrm{N}, \mathrm{S})$ \\
\hline $\mathbf{A C}$ & $+0.023(\mathrm{t}=5.99$, Ap.N, NS $)$ & TFIR & $-0.113 *(t=-2.73, N, S)$ \\
\hline AMWS & $+0.116(\mathrm{t}=3.84, \mathrm{NN}, \mathrm{NS})$ & ARH(0-12) & $-\underline{0.052}(\mathrm{t}=-1.71, \mathrm{~N}, \mathrm{~S})$ \\
\hline AWBT & $+0.020(\mathrm{t}=3.36, \mathrm{NN}, \mathrm{S})$ & TFZR & $-0.639(\mathrm{t}=-3.12, \mathrm{~N}, \mathrm{NS})$ \\
\hline TR & $+2.39(\mathrm{t}=1.82, \mathrm{NN}, \mathrm{S})$ & $\mathbf{A E}$ & $-0.777(\mathrm{t}=-1.75, \mathrm{NN}, \mathrm{S})$ \\
\hline MXR & $+0.424(\mathrm{t}=0.99, \mathrm{NN}, \mathrm{NS})$ & ASLP & $-0.0004(\mathrm{t}=-0.04, \mathrm{NN}, \mathrm{S})$ \\
\hline AMNT & $+0.006(\mathrm{t}=0.79, \mathrm{NN}, \mathrm{S}$ & ASSH & $-0.030(\mathrm{t}=-1.01, \mathrm{~N}, \mathrm{~S})$ \\
\hline
\end{tabular}

Table 8 presents the rates of LT for Kharif climatic variables and the Residual's Stationarity and Normality. During Kharif season, the significant positive growth rates are established for ADBT $\left(+0.00655^{*}\right)$ but negative for TFZR (-0.0846*); approximately significant positive for $\operatorname{ARH}(0-12)(+\underline{0.0224})$ but negative for $\mathrm{AE}(-\underline{0.538)}$ and TFIR (-0.117). The fairly high positive rates are observed for $\mathrm{ARH}(0)(+0.055)$, $\mathrm{AC}(+0.012)$, $\mathrm{AST}(5)(+0.063)$,
AWBT (+0.008), AMWS (+0.042), MXR (+2.83), ARH(12) (+0.0329), TR (+7.53), ASLP $(+0.0075)$ and less positive for AMNT $(+0.00325)$ and ARH $(+0.007)$ but less negative for AT (D-W) (-0.0015), AMXT (-0.0011) and ARNT (-0.002) with nonnormal and/or nonstationary residual. The less negative rate is accredited for ASSH (0.007 ) with normal and/or stationary residual.

Table 8. Rates of LT for the data of kharif season and the residual's stationarity and normality

\begin{tabular}{|l|l|l|l|}
\hline Variable & \multicolumn{1}{|c|}{ Kharif } & Variable & \multicolumn{1}{c|}{ Kharif } \\
\hline ADBT & $+0.00655^{*}(\mathrm{t}=2.61, \mathrm{Ap} . \mathrm{N}, \mathrm{S})$ & ASLP & $+0.0075(\mathrm{t}=1.09, \mathrm{~S}, \mathrm{NN})$ \\
\hline ARH $(\mathbf{0}-\mathbf{1 2})$ & $+\underline{0.0224}(\mathrm{t}=1.57, \mathrm{Ap} . \mathrm{N}, \mathrm{S})$ & AMNT & $+0.00325(\mathrm{t}=0.59, \mathrm{NN}, \mathrm{S})$ \\
\hline ARH $(\mathbf{0})$ & $+0.0552(\mathrm{t}=6.67, \mathrm{NN}, \mathrm{S})$ & ARH & $+0.0073(\mathrm{t}=0.36, \mathrm{NN}, \mathrm{Ap} . \mathrm{S})$ \\
\hline AC & $+0.0124(\mathrm{t}=4.49, \mathrm{~N}, \mathrm{NS})$ & TFZR & $-0.0846 *(\mathrm{t}=-4.47$, Ap.N, Ap.S $)$ \\
\hline AST(5cm) & $+0.0635(\mathrm{t}=3.72, \mathrm{~N}, \mathrm{NS})$ & AE & $\underline{-0.538}(\mathrm{t}=-1.90, \mathrm{~N}, \mathrm{~S})$ \\
\hline AWBT & $+0.00812(\mathrm{t}=2.30, \mathrm{NN}, \mathrm{S})$ & TFIR & $\underline{-0.117}(\mathrm{t}=-1.83, \mathrm{~N}, \mathrm{~S})$ \\
\hline AMWS & $+0.0424(\mathrm{t}=1.94, \mathrm{NN}, \mathrm{NS})$ & AT(D-W) & $-0.00157(\mathrm{t}=-0.52, \mathrm{NN}, \mathrm{NS})$ \\
\hline MXR & $+2.83(\mathrm{t}=1.83, \mathrm{NN}, \mathrm{NS})$ & AMXT & $-0.00118(\mathrm{t}=0.29, \mathrm{NN}, \mathrm{NS})$ \\
\hline ARH $(\mathbf{1 2})$ & $+0.0329(\mathrm{t}=1.72, \mathrm{NN}, \mathrm{S})$ & ARNT & $-0.00208(\mathrm{t}=-0.29, \mathrm{NN}, \mathrm{S})$ \\
\hline TR & $+7.53(\mathrm{t}=1.57, \mathrm{NN}, \mathrm{NS})$ & ASSH & $-0.0071(\mathrm{t}=-0.25, \mathrm{~N}, \mathrm{~S})$ \\
\hline
\end{tabular}

Table 9 presents the rates of LT for coefficient of variations of Rabi climatic variables with their respective ' $t$ ' values, residual's stationarity and normality. During Rabi season, the significant positive rates for the variations of ARH (0-12) $(+0.296 *)$, AMXT $(+0.098 *)$ and ADBT $(+0.053 *)$ and approximately significant for TFZR $(+\underline{0.025})$ but significant negative for ARH(0) $\left(-0.043^{*}\right)$; fairly high positive rates for ASSH $(+0.38)$ and less positive for
AWBT (+0.017) AMNT (+0.0252) AE (+0.177) but fairly high negative for ARH (12) (-0.0439) and less negative for ASLP (-0.0003) with normal and stationary residual. The fairly high positive rate is observed for AST (5) $(+0.208)$ but negative for ARH $(-0.0584)$ and AT (D-W) (-0.0514) and less negative for ARNT (-0.03) with nonnormal and/or nonstationary residual. 


\section{J. Environ. Sci. \& Natural Resources, 5(1): 19-28, 2012}

Table 9. Rates of LT for the CVs of the data of rabi season and residual's stationarity and normality

\begin{tabular}{|l|l|l|l|}
\hline Variable & \multicolumn{1}{|c|}{ Rabi } & \multicolumn{1}{|c|}{ Variable } & \multicolumn{1}{c|}{ Rabi } \\
\hline ARH $(\mathbf{0}-12)$ & $+0.296^{*}(\mathrm{t}=4.16, \mathrm{~N}, \mathrm{~S})$ & AST $(\mathbf{5})$ & $+0.208(\mathrm{t}=2.18, \mathrm{NN}, \mathrm{S})$ \\
\hline AMXT & $+0.098^{*}(\mathrm{t}=6.33, \mathrm{Ap} . \mathrm{N}, \mathrm{S})$ & $\mathbf{A R H}(\mathbf{0})$ & $-0.043^{*}(\mathrm{t}=-3.86, \mathrm{~N}, \mathrm{~S})$ \\
\hline ADBT & $+0.053^{*}(\mathrm{t}=3.14, \mathrm{~N}, \mathrm{~S})$ & $\mathbf{A R H}(\mathbf{1 2})$ & $-0.0439(\mathrm{t}=-1.13, \mathrm{~N}, \mathrm{~S})$ \\
\hline TFZR & $+\underline{\underline{0.025}}(\mathrm{t}=1.63, \mathrm{Ap} . \mathrm{N}, \mathrm{S})$ & ASLP & $-0.0003(\mathrm{t}=-0.77, \mathrm{~N}, \mathrm{~S})$ \\
\hline ASSH & $+0.38(\mathrm{t}=1.18, \mathrm{Ap} . \mathrm{N}, \mathrm{S})$ & ARH & $-0.0584(\mathrm{t}=-2.60, \mathrm{NN}, \mathrm{S})$ \\
\hline AWBT & $+0.017(\mathrm{t}=0.85, \mathrm{~N}, \mathrm{~S})$ & AT(D-W) & $-0.0514(\mathrm{t}=-1.02, \mathrm{NN}, \mathrm{NS})$ \\
\hline AMNT & $+0.0252(\mathrm{t}=0.82, \mathrm{~N}, \mathrm{~S})$ & ARNT & $-0.03(\mathrm{t}=-0.89, \mathrm{NN}, \mathrm{S})$ \\
\hline AE & $+0.177(\mathrm{t}=0.53, \mathrm{Ap} . \mathrm{N}, \mathrm{S})$ & TR & \\
\hline
\end{tabular}

Table 10 presents the rates of LT for coefficient of variations of Prekharif climatic variables with their respective ' $t$ ' values, residual's stationarity and normality. During Prekharif season, the significant negative rates are observed for ARH (0) $\left(-0.116^{*}\right)$, ARH (12) (-0.324*), ARH (-0.199*) and AWBT ($0.07 *)$ and approximately significant negative rate for AT(D-W) (-0.155). The relatively high negative rate is found for ARNT (-0.0615) with normal and stationary residual and for AMNT (-0.0567) and ASLP (-0.0017) with nonnormal and stationary residual where as the relatively high positive rate for TFZR (+0.19) with nonnormal and stationary residual. The less negative rates are found for ADBT $(-0.016)$ and ARH (0-12) (-0.056) but positive for AST (5) (+0.070) with normal and stationary residual where as less positive for AMXT (+0.014) and ASSH $(+0.028)$ with nonnormal and stationary residual.

Table 10. Rates of LT for the CVs of the data of prekharif season and residual's stationarity and normality

\begin{tabular}{|c|c|c|c|}
\hline Variable & Prekharif & Variable & Prekharif \\
\hline TR & - & $\operatorname{ARH}(0-12)$ & $-0.056(\mathrm{t}=-0.61$, Ap.N, $\mathrm{S})$ \\
\hline $\mathbf{A R H}(\mathbf{0})$ & $-0.116^{*}(\mathrm{t}=-5.03, \mathrm{~N}, \mathrm{~S})$ & AMNT & $-0.0567(\mathrm{t}=-2.24, \mathrm{NN}, \mathrm{S})$ \\
\hline ARH(12) & $-0.324 *(\mathrm{t}=-4.86, \mathrm{~N}, \mathrm{~S})$ & ASLP & $-0.0017(\mathrm{t}=-1.81, \mathrm{NN}, \mathrm{S})$ \\
\hline ARH & $-0.199 *(\mathrm{t}=-4.51$, Ap.N,S $)$ & $\mathbf{A E}$ & $-0.182(\mathrm{t}=-0.41, \mathrm{NN}, \mathrm{NS})$ \\
\hline AWBT & $-0.07 *(\mathrm{t}=-3.49$, Ap. $\mathrm{N}, \mathrm{S})$ & TFZR & $+0.19(\mathrm{t}=2.42, \mathrm{NN}, \mathrm{S})$ \\
\hline $\mathbf{A T}(\mathbf{D}-\mathbf{W})$ & $-\underline{-0.155}(\mathrm{t}=-1.80, \mathrm{Ap} . \mathrm{N}, \mathrm{S})$ & AMXT & $+0.014(\mathrm{t}=0.89, \mathrm{NN}, \mathrm{S})$ \\
\hline ARNT & $-0.0615(\mathrm{t}=-1.23, \mathrm{~N}, \mathrm{~S})$ & ASSH & $+0.028(\mathrm{t}=0.06, \mathrm{NN}, \mathrm{S})$ \\
\hline ADBT & $-0.016(\mathrm{t}=-0.68, \mathrm{~N}, \mathrm{~S})$ & AST(5) & $+0.070(\mathrm{t}=0.48, \mathrm{~N}, \mathrm{~S})$ \\
\hline
\end{tabular}

Table 11 presents the rates of LT for coefficient of variations of Kharif climatic variables with their respective ' $t$ ' values, residual's stationarity and normality. During Kharif season, the relatively high positive rates are found for ADBT, TFZR and AMXT but negative rates are observed for ARH (0-12) and
ARNT whereas less positive for AMNT, AWBT, AST (5), ASSH, ARH (12) and less negative for TR, ASLP, AT (D-W), AE, ARH and ARH (0) with normal/stationary or nonnormal and/or nonstationary residual.

Table 11. Rates of LT for the CVs for the data of kharif season and residual's stationarity and normality

\begin{tabular}{|l|l|l|l|}
\hline Variable & Kharif & Variable & Kharif \\
\hline ADBT & $+0.0097(\mathrm{t}=1.16, \mathrm{~N}, \mathrm{~S})$ & ARH $(\mathbf{0}-12)$ & $-0.101(\mathrm{t}=-1.64, \mathrm{NN}, \mathrm{S})$ \\
\hline TFZR & $+0.31(\mathrm{t}=1.83, \mathrm{NN}, \mathrm{NS})$ & ARNT & $-0.052(\mathrm{t}=-1.12, \mathrm{NN}, \mathrm{S})$ \\
\hline AMXT & $+0.008(\mathrm{t}=1.02, \mathrm{Ap} . \mathrm{N}, \mathrm{NS})$ & TR & $-0.16(\mathrm{t}=-0.99, \mathrm{NN}, \mathrm{Ap} . \mathrm{S})$ \\
\hline AMNT & $+0.0149(\mathrm{t}=0.79, \mathrm{NN}, \mathrm{S})$ & ASLP & $-0.0006(\mathrm{t}=-0.76, \mathrm{NN}, \mathrm{S})$ \\
\hline
\end{tabular}




\begin{tabular}{|l|l|l|l|}
\hline AWBT & $+0.005(\mathrm{t}=0.42, \mathrm{NN}, \mathrm{S})$ & AT(D-W) & $-0.035(\mathrm{t}=-0.63, \mathrm{NN}, \mathrm{S})$ \\
\hline AST(5) & $+0.016(\mathrm{t}=0.33, \mathrm{NN}, \mathrm{S})$ & AE & $-0.2(\mathrm{t}=-0.56, \mathrm{NN}, \mathrm{S})$ \\
\hline ASSH & $+0.032(\mathrm{t}=0.07, \mathrm{~N}, \mathrm{~S})$ & ARH & $-0.0056(\mathrm{t}=-0.26, \mathrm{NN}, \mathrm{S})$ \\
\hline ARH(12) & $+0.0013(\mathrm{t}=0.06, \mathrm{NN}, \mathrm{S})$ & ARH $(\mathbf{0})$ & $-0.00050(\mathrm{t}=-0.07, \mathrm{NN}, \mathrm{S})$ \\
\hline
\end{tabular}

\section{Conclusions}

The foregoing analyses indicate that during Rabi season, the significant positive rates are documented for AWBT $\left(+0.0237^{*}\right)$, AC $\left(+0.0136^{*}\right)$ and AMNT $\left(+0.0175^{*}\right)$ but significant negative for ARNT ($\left.0.0456^{*}\right)$, AMXT $\left(-0.0281^{*}\right)$ and TFZR $\left(-0.0180^{*}\right)$ and approximately negative for $\mathrm{AE}(-\underline{-0.196})$ and ASLP (-0.0068). The fairly high positive rates for ARH (12) (+0.282), ARH (0) (+0.160), AMWS (+ $0.0856)$ ARH (+0.126), MXR (+0.414), TR (+0.547), AST (5) (+0.0760) and ADBT (+0.0108) but negative for ARH (0-12) (-0.122), AT(D-W) (-0.0129) and TFIR (-0.0310) and less negative for ASSH (-0.0125) with nonnormal and/or nonstationary residual, respectively.

During Prekharif season, the significant positive growth rates are allowed for ARH $(0)\left(+0.219^{*}\right)$, ARH $\left(+0.252^{*}\right)$ and ARH (12) $(+0.271 *)$ but negative for ARNT $\left(-0.0538^{*}\right)$, AT (D-W) $\left(-0.0476^{*}\right)$, AMXT $\left(-0.0475^{*}\right)$, ADBT $\left(-0.0270^{*}\right)$ and TFIR $\left(-0.113^{*}\right)$; approximately significant positive for AST (5) $\underline{(+0.0880)}$ but negative for ARH (0-12) (-0.0521); fairly high positive rates for AC (+ 0.0234), AMWS $(+0.116)$, AWBT $(+0.0207)$ and TR $(+2.39)$ but negative for TFZR (-0.639) and AE (-0.777) with nonnormal and/nonstationary residual; less positive for MXR (+0.424) and AMNT (+0.00625) but negative for ASLP (-0.00041) with nonnormal and/nonstationary residual. The negative growth rates are permitted for ASSH (-0.030) with normal and stationary residual.

During Kharif season, the significant positive growth rates are established for ADBT $\left(+0.00655^{*}\right)$ but negative for TFZR $\left(-0.0846^{*}\right)$; approximately significant positive for $\mathrm{ARH}(0-12)(+\underline{0.0224})$ but negative for $\mathrm{AE}(-\underline{0.538)}$ and TFIR (-0.117). The fairly high positive rates are observed for $\mathrm{ARH}(0)$ $(+0.055), \mathrm{AC}(+0.012), \mathrm{AST}(5)(+0.063), \quad$ AWBT $(+0.008)$, AMWS (+0.042), MXR (+2.83), ARH(12) $(+0.0329), \quad \mathrm{TR}(+7.53)$, ASLP $(+0.0075)$ and less positive for AMNT (+0.00325) and ARH(+0.007) but less negative for AT(D-W) (-0.0015), AMXT ($0.0011)$ and ARNT (-0.002) with nonnormal and/or nonstationary residual. The less negative rate is accredited for ASSH (-0.007) with normal and/or stationary residual.
Some residuals demonstrate stationary pattern but several follow nonstationarity and a few error support normal distribution but others show nonnormality. Sometimes robust and non-robust measures come up with conflicting conclusions. So it is imperative for us to avoid normality assumption based statistical procedures for further analysis of historical climatic data and emphasize the view in favor of EDA and robust techniques in analyzing climatic variables. Significant changes in some variables support that the climate of Dinajpur district is changing, which ultimately may affect its agricultural production.

\section{References}

Ahmed, R. and Karmakar, S. 1993. Arrival and withdrawal dates of the summer monsoon in Bangladesh. International Journal of Climatology, 13: 727-740.

Ali, M. M., Ahmed, M., Talukder, M. S. U. and Hye, M. A. 1994. Rainfall distribution and agricultural droughts influencing cropping pattern at Mymensingh region. Progressive Agriculture, 5: 197-204.

Imon, A. H. M. R. 2003. "Regression Residuals, Moments and their use in tests for normality", Communications in Statistics - Theory and methods, 32: 1021-1034.

Karmakar, S. 2001. Global warming and recent climatic changes in Bangladesh, presented in an workshop on climatology and meteorology, Dhaka.

Lenka, D. 1998. Climate Weather and Crops in India, 23 Daryagang, New Delhi-110002. 5 p.

Rahman, M S and Alam M. S. 1996. Patterns of rainfall variability and trend in the high Barind region, Rajshahi University Studies Part-B, Journal of Science, 24.

Talukder, M. S. U.; Ali, M. A.; Huq, M. M. and Hossain, M. A. (1988) " A study on rainfall pattern in Bangladesh", Bangladesh Journal of Agricultural Sciences, 15: 217-224.

Tukey, J. 1977 Exploratory Data Analysis, AddisonWesley, New York. 